\title{
HIGH BIREFRINGENCE NEMATIC LIQUID CRYSTALS FOR DISPLAY AND TELECOM APPLICATIONS
}

\author{
Carmen Otilia Catanescu and L.-C. Chien* \\ Liquid Crystal Institute, Kent State University, Kent, \\ Ohio 44242, USA \\ Shin-Tson Wu \\ School of Optics/CREOL, University of Central Florida, Orlando, \\ Florida 32816, USA
}

\begin{abstract}
Several compounds with high birefringence and having tolane structure were synthesized. For a high polarizability, isothiocyanato (NCS) terminal group was introduced. Another goal of this study was reduction of melting point and smectic phases by introduction of fluorine as lateral substituent. The transition temperatures for all the synthesized compounds and the refractive and dielectric indices for one of the compounds have been determined. Electro-optic (EO) measurements were also performed.
\end{abstract}

Keywords: birefringence; electro-optics; nematic; synthesis; tolanes

\section{INTRODUCTION}

Certain properties of display applications such as response time, viewing angle, voltage holding ratio (VHR), power consumption, operation temperature ranges still need to be improved without affecting general properties in a negative way [1-3]. Liquid crystal (LC) single compound cannot achieve all the desired parameters, therefore LC mixtures are employed. Usually, LC mixtures consist of about 10-20 individual LC compounds designed for particular applications.

LC materials with high dielectric anisotropy $(\Delta \varepsilon)$ can be realized by introducing fluorine atoms in the compound's structure. Fluorinated LCs also contribute to the decreasing of optical anisotropy which leads to a 
better viewing angle. An appropriate selection of the fluorine atom's position can lower the viscosity, reduce melting points, depress the temperature of smectic phase formation and improve solubility and stability $[2,4,5]$. For almost all display applications, a faster response time is required. The response time is directly proportional to the rotational viscosity and the square of the cell thickness, d. As the product of cell thickness $\mathrm{d}$ and the birefringence $\Delta \mathrm{n}$ is fixed for a certain set of cell parameters improved response time can be achieved by increasing the $\Delta \mathrm{n}$ value of the mixtures.

In general, long wavelength light has been used for telecom applications because of lowest absorption and light efficiency. To steer a $\lambda=1.55 \mu \mathrm{m}$ laser beam, the required $2 \pi$ phase change $(\delta=2 \pi \mathrm{d} \Delta \mathrm{n} / \lambda)$ leads to $\mathrm{d} \Delta \mathrm{n} \sim 1.6$. In order to achieve fast response time while keeping high manufacturing yield, the cell gap is normally kept at $\mathrm{d} \sim 4 \mu \mathrm{m}$. Thus, LC mixtures with $\Delta \mathrm{n} \geq 0.4$ and low viscosity, low optical loss, wide nematic range, excellent thermal stability, and low operating voltage are particularly desirable. In the case of telecom optical switch applications, for $\lambda=1.55 \mu \mathrm{m}$ and $90^{\circ} \mathrm{TN}$ cell, $\Delta \mathrm{n}$ should be approximately 0.35 , if $\mathrm{d}=4 \mu \mathrm{m}$.

In the search for new materials with improved properties several tolanes having fluorine atoms and NCS terminal group were synthesized based on the fact that tolane substances have proved to have a better combination of physical properties than other materials [6]. The saturated alkyl chain was linked with the rigid core through oxygen or sulfur atom. Just three compounds exhibit nematic phase, all other compounds having crystalline structure. Four LC mixtures were formulated using the new tolane compounds having ether linkage. Electro-optical properties and UV stability of some of the synthesized compounds were investigated.

\section{EXPERIMENTAL}

Confirmation of the structures of the intermediates and the final products was obtained by ${ }^{1} \mathrm{H}-\mathrm{NMR}$ spectroscopy using a Varian Gemini $200 \mathrm{MHz}$ spectrometer with tetramethylsilane as internal standard. IR spectra were recorded using a Nicolet Magna 550 FT-IR spectrometer (NaCl crystal window). Thin-layer chromatography was performed using aluminium sheets silica gel $60 \mathrm{~F}_{254}$ (Merck) and were examined under UV light. Column chromatography was performed under gravity using Merck's Silicagel 60 .

Melting points of final products were determined using a ThomasHoover Capillary Melting Point Apparatus. Transition temperatures were determined using a Mettler FP52 heating stage and FP5 temperature control unit in conjunction with a Nikon polarizing optical microscope, and the transitions were confirmed by DSC analysis (Perkin Elmer Pyris 1, Perkin Elmer TAC 7/DX, Perkin Elmer Intracooler 2P). Heating and 
cooling cycles were run at rates of $2^{\circ} \mathrm{C} /$ min under nitrogen atmosphere with samples measured in closed lid aluminium pans. Mesophase type was assigned by visual comparison (under the microscope) with known phase standards.

The dielectric anisotropies $\left(\Delta \varepsilon=\varepsilon_{\|}-\varepsilon_{\perp}\right)$ of compound 5 were measured by the capacitance method at a frequency of $1 \mathrm{kHz}(\lambda=633 \mathrm{~nm})$ using a computer-controlled APT III instrument (manufactured by Displaytech). The measurements were carried out at a fixed temperature $\mathrm{T}=295 \mathrm{~K}, 20 \%$ of the compound being dissolved in a Merck LC mixture (ZLI-3086 with $\Delta \varepsilon \sim 0$ ) as a host.

The birefringence $\left(\Delta \mathrm{n}=\mathrm{n}_{\mathrm{e}}-\mathrm{n}_{\mathrm{o}}\right)$ of the same compound was measured using a He-Ne laser $(\lambda=633 \mathrm{~nm})$ at $\mathrm{T}=295 \mathrm{~K}, 20 \%$ of it being dissolved in a low birefringence LC host (ZLI-14600-100). In both cases, the $\Delta \varepsilon$ and $\Delta \mathrm{n}$ values were extrapolated to $100 \%$ concentration. The UV spectrum of compound 7 was recorded on a Hewlett-Packard HP-8453 diode-array spectrophotometer using chloroform as solvent. The UV stability of the NCS based tolanes (15\% of compound 7 mixed with E48 Merck LC mixture - designated as LC1) was investigated using a metal halide lamp that illuminate a $4 \mu \mathrm{m}$ anti-parallel cell for $600 \mathrm{sec}\left(\sim 4.8 \mathrm{~J} / \mathrm{cm}^{2}\right.$ esposure dosage).

Two anti-parallel cells with PI 2555 as the alignment layer and $3.7 \mu \mathrm{m}$ and $4.1 \mu \mathrm{m}$ thickness were prepared for the electro-optical studies. The transmittance vs. applied voltage and transmittance vs. time curves were recorded using a HeNe laser beam $(\lambda=633 \mathrm{~nm})$, under parallel polarizor and analyzor and sample at $45^{\circ}$ (rubbing direction).

\section{SYNTHESIS}

Ten novel compounds were prepared according to the procedure detailed in Scheme 1. All homologues were synthesized using the same method, but the general experimental procedures will be published elsewhere. Alkyloxy/sulfanil bromobenzenes (a) were synthesized using Williamson's etherification in near-quantitative yields. Compound $\mathbf{b}$ was converted into the alkyne $\mathbf{c}$ via compound $\mathbf{b}$ by using the 2-methylbut-3-yn-2-ol method.

Palladium-catalysed coupling reaction of alkyne with the 4-bromo-2, 6-difluoro-aniline gave compound $\mathbf{d}$ in low yields, but its conversion in the final compound (e) gave quantitative yields. We present here the experimental method just for the final product with $n=4$ (1-(4-Butyloxyphenyl)-2-(3,5-difluoro-4-isothiocyanato phenyl) ethyne)-compound 5.

\section{1-(4-Butyloxyphenyl)-2-(3,5-difluoro-4-isothiocyanato phe- nyl) ethyne 5e}

A solution of compound $5 \mathrm{~d}(2.4 \mathrm{~g} ; 7.97 \mathrm{mmol})$ in chloroform $\left(30 \mathrm{~cm}^{3}\right)$ was added dropwise at $0-5^{\circ} \mathrm{C}$ to a stirred, cooled $\left(0^{\circ} \mathrm{C}\right)$ mixture of water 

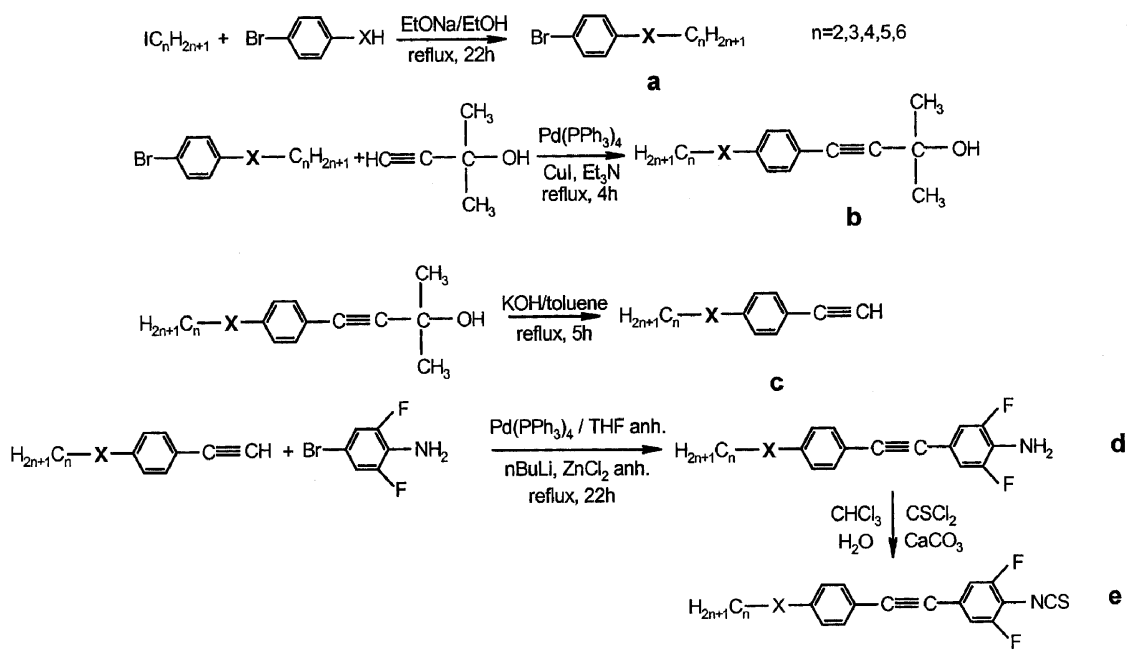

$\mathrm{X}=\mathrm{O}, \mathrm{S}$

SCHEME 1 Synthesis of NCS based tolanes.

$\left(18 \mathrm{~cm}^{3}\right)$, chloroform $\left(9 \mathrm{~cm}^{3}\right)$, calcium carbonate $(1.25 \mathrm{~g} ; 12.5 \mathrm{mmol})$, and thiophosgene $\left(0.65 \mathrm{~cm}^{3} ; 85 \mathrm{mmol}\right)$. Then the mixture was heated at reflux for $16 \mathrm{~h}$ and poured into water $\left(100 \mathrm{~cm}^{3}\right)$, and the separated organic layer was quenched with hydrochloric acid $\left(45 \mathrm{~cm}^{3} ; 1 \%\right)$, and dried over sodium sulfate anh. The solvent was removed in vacuo. The product was purified by column chromatography (hexane) and recrystallized from hexane to give white crystals. Yield 83.82\%. ${ }^{1} \mathrm{H}-\mathrm{NMR}\left(\mathrm{CDCL}_{3}\right) \delta$, ppm $0.98(3 \mathrm{H}, \mathrm{t})$, 1.47 (2H, sext.), 1.78 (2H, quint.), 3.97 (2H, t), 6.89 (2H, sext.), 7.094 ( $2 \mathrm{H}$, sext.), 7.45 (2H, sext.). IR (film in nujol) $v_{\max } / \mathrm{cm}^{-1} 722,1051$, 1175, 1255, 1380, 1466, 1518, 1611, 2032, 2098, 2216, 2854, 2920, 2966.

\section{RESULTS AND DISCUSSION}

DSC thermograms for compounds 1,3,5,7,9 are shown in Figure 1. Transition temperatures and extrapolated physical properties for materials 1-10 are reported in Table I. As one can see, just three compounds (with ether linkage) exhibit mesomorphic properties in a narrow nematic temperature range. All the synthesized materials show relatively high $\Delta \mathrm{H}$ and low melting points, the longer the alkyl chain, the lower the clearing point. Compounds with $n=2,3$ have higher melting points than all other substances, but with longer chain one can observe the classical "odd-even" 


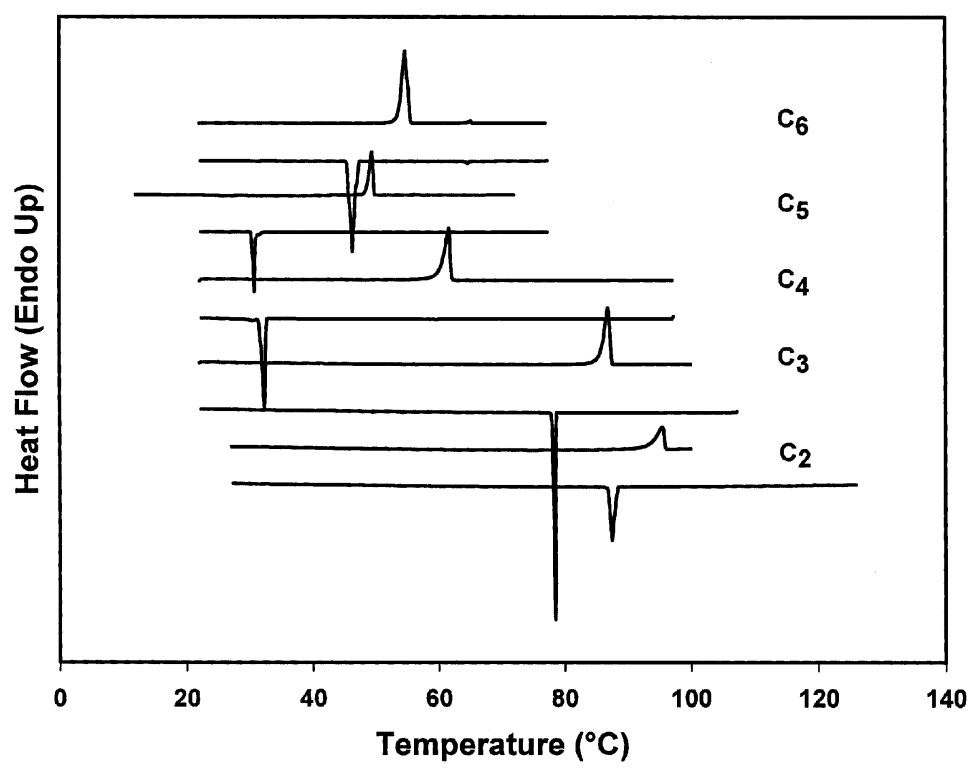

FIGURE 1 DSC thermograms of compounds 1,3,5,7,9.

effect of alkyl chain length upon the melting point. Low melting points usually gives a good solubility in LC host.

The exchange of oxygen atom with sulfur one led to a decrease in transition temperatures of all homologues, in some cases with even $22^{\circ} \mathrm{C}$ (compound 8). This effect appears due to the change in the $\mathrm{L} / \mathrm{D}$ ratio of the compounds containing sulfur atom because of its bigger volume compared with the oxygen atom.

TABLE I Transition Temperatures and Some Physical Properties

\begin{tabular}{|c|c|c|c|c|c|}
\hline No. & $n$ & $\mathrm{X}$ & $\Delta \mathrm{H}(\mathrm{kcal} / \mathrm{mol})$ & Phase transitions $\left({ }^{\circ} \mathrm{C}\right)$ & Physical properties \\
\hline 1 & 2 & $\mathrm{O}$ & 5.93 & K 95.4 I & \\
\hline 2 & 2 & $\mathrm{~S}$ & 7.91 & K 89.6 I & \\
\hline 3 & 3 & $\mathrm{O}$ & 7.79 & K 86.8 I & \\
\hline 4 & 3 & $\mathrm{~S}$ & 7.73 & K 80.8 I & \\
\hline 5 & 4 & $\mathrm{O}$ & 6.67 & K 61.6 N (59.7) & $\Delta \mathrm{n}=0.41 \Delta \varepsilon=18$ \\
\hline 6 & 4 & $\mathrm{~S}$ & 6.95 & K 58.4 I & \\
\hline 7 & 5 & $\mathrm{O}$ & 7.07 & K 49.5 N 56.6 I & \\
\hline 8 & 5 & $\mathrm{~S}$ & 6.33 & K 34.4 I & \\
\hline 9 & 6 & $\mathrm{O}$ & 8.57 & K 54.7 N $65.1 \mathrm{I}$ & \\
\hline 10 & 6 & $\mathrm{~S}$ & 9.04 & K 55.5 I & \\
\hline
\end{tabular}




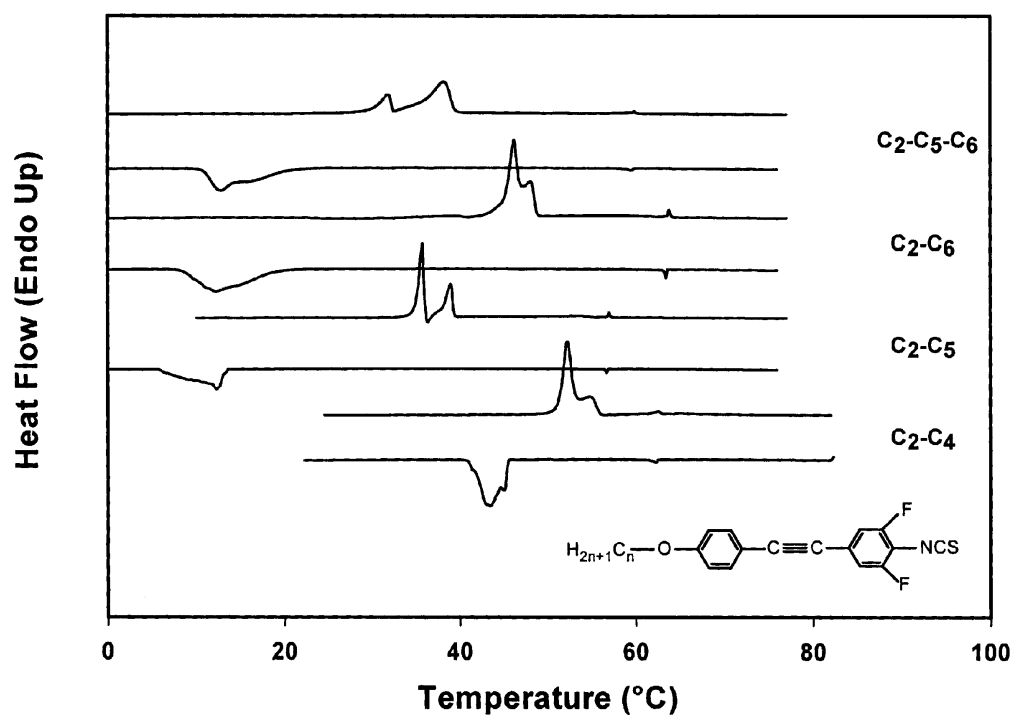

FIGURE 2 DSC thermograms of LC mixtures.

The birefringence of compound 5 was measured using the guest-host method to extrapolate its $\Delta \mathrm{n}$ value, $20 \%$ of the compound being dissolved in ZLI-14600-100; $\Delta \mathrm{n}=0.41$ was found. The dielectric anisotropy of the same compound was found to be $\Delta \varepsilon=18$. Both properties have relatively large values due to the presence of NCS and fluoro groups.

Three binary and one ternary LC mixtures were formulated using compounds 1, 5, 7 and 9. Their nematic behavior was predicted using a computer program based on the Schroder van Laar equation and compared with DSC thermograms of the mixtures as shown in Figure 2 and presented in Table 2.

TABLE II Mesophase Behavior of the LC Mixtures

\begin{tabular}{lcc}
\hline $\begin{array}{l}\text { Mixture composition } \\
(\text { wt\% })\end{array}$ & $\begin{array}{c}\text { Predicted nematic } \\
\text { range }\left({ }^{\circ} \mathrm{C}\right)\end{array}$ & $\begin{array}{c}\text { Observed nematic } \\
\left.\text { range* }^{\circ}{ }^{\circ} \mathrm{C}\right)\end{array}$ \\
\hline $\mathrm{C} 2 / \mathrm{C} 4=34.5 / 65.5$ & $54.0-73.4$ & $52.2-62.6$ \\
$\mathrm{C} 2 / \mathrm{C} 5=23 / 77$ & $41.2-66.4$ & $35.7-57.0$ \\
$\mathrm{C} 2 / \mathrm{C} 6=26.1 / 73.9$ & $46.3-74.0$ & $46.2-63.8$ \\
$\mathrm{C} 2 / \mathrm{C} 5 / \mathrm{C} 6=15.8 / 48.9 / 35.3$ & $30.0-66.0$ & $31.8-59.9$ \\
\hline
\end{tabular}

*DSC data. 
The Schroder van Laar equation relates the melting point (T) of a mixture to the mole fraction $\left(\mathrm{x}_{\mathrm{A}}\right)$ of component A[3]. In Eq. (1) $\mathrm{H}_{\mathrm{A}}$ and $\mathrm{T}_{\mathrm{A}}$ are the latent heat of melting and melting point of the pure component, $\mathrm{R}$ is the gas constant.

$$
\ln \mathrm{x}_{\mathrm{A}}=\frac{\mathrm{H}_{\mathrm{A}}}{\mathrm{R}}\left(\frac{1}{\mathrm{~T}_{\mathrm{A}}}-\frac{1}{\mathrm{~T}}\right)
$$

For a mixture of $\mathrm{N}$ components there are $\mathrm{N}$ such equations, which when solved for the condition shown in Eq. (2) give the temperature and mole fractions of the eutectic composition This method occasionally predicts the mole fractions of the eutectic mixture fairly well, but because ideal behavior rarely exists it can only be used as a guide.

$$
\sum_{i=A}^{N} x_{j}=1
$$

The clearing point of mixtures can be calculated using Eq. (3)

$$
\mathrm{T}_{\mathrm{c}}=\sum_{\mathrm{i}=\mathrm{A}}^{\mathrm{N}} \mathrm{x}_{\mathrm{i}} \mathrm{T}_{\mathrm{ci}}
$$

where $\mathrm{x}_{\mathrm{i}}$ is the mole fraction of the component in the mixture and $\mathrm{T}_{\mathrm{ci}}$ is the clearing point of the component. However, this relationship holds best when compounds of similar polarity are mixed.

The observed nematic range was approximately in the same range with the predicted one. In these mixtures one can see that the mesophase was expanded or even induced compared with the pure compounds.

All mixtures are enantiotropic liquid crystals; the last three ones (C2-C5, C2-C6 and C2-C5-C6) have very low crystallization temperature, below room temperature and the mesophase range is quite large (around $40^{\circ} \mathrm{C}$ on cooling). All four mixtures show two peaks when melting or crystallizing and that could mean a smectic phase, but it wasn't confirmed, but usually, when mixing two polar compounds, a smectic phase is induced.

The differences between the estimated values of the nematic range and experimental data are $8-10^{\circ} \mathrm{C}$ in average, with the exception of mixture $\mathrm{C} 2 / \mathrm{C} 5$ where this difference is smaller $\left(\sim 4^{\circ} \mathrm{C}\right)$ - the experimental $\mathrm{T}_{\mathrm{NI}}$ value is $35.7^{\circ} \mathrm{C}$ instead of predicted $41.2^{\circ} \mathrm{C}$.

Electro-optical properties as transmittance vs. applied voltage and transmittance vs. time were performed for compound 7 (15\% of it being dissolved in commercial Merck LC mixture E48) - abbreviated LC1. In order to be able to compare the LC1 mixture with the host LC mixture - abbreviated LC2 - we used anti-parallel rubbed cells with cell gap of $3.7 \mu \mathrm{m}$ for the LC1 mixture and $4.1 \mu \mathrm{m}$ for LC2, respectively. The results 


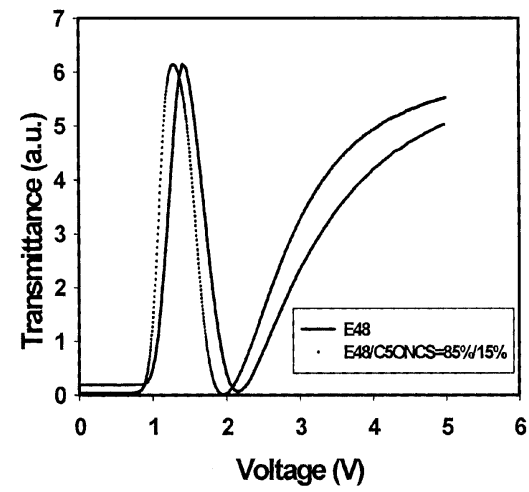

(a)

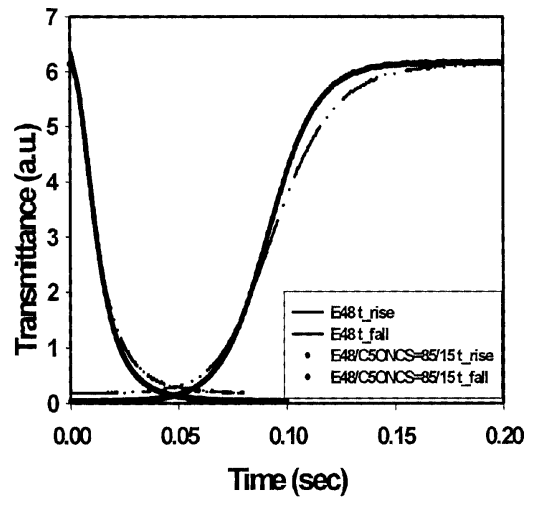

(b)

FIGURE 3 a) T-V curve for LC1 (abbreviated E48/C5ONCS in the figure's legend) and LC2; b) T-t curve for LC1 and LC2.

are shown in Figure 3. The switching times were measured by applying a square-wave AC voltage of $1.3 \mathrm{~V}$ for $\mathrm{LC} 1$ and $1.45 \mathrm{~V}$ for LC2 mixture, respectively at $1 \mathrm{kHz}$. The switching-on time or rising time ( $\tau_{\text {on }}$ or $\tau_{\text {rise }}$ ) and switching-off time or falling time ( $\tau_{\text {off }}$ or $\left.\tau_{\text {fall }}\right)$ were defined as the switching times between $10 \%$ and $90 \%$ transmittance.

Table III summarizes the results of electro-optical studies for these mixtures. As one can see, the LC1 mixture containing compound 7 has smaller values of threshold voltage $\left(\mathrm{V}_{10}\right)$, saturation voltage $\left(\mathrm{V}_{90}\right)$, rising time $\left(\tau_{\text {rise }}\right)$, falling time $\left(\tau_{\text {rise }}\right)$, and contrast ratio $\left(V_{90} / V_{10}\right)$ compared with the host LC, yet the differences are too small. This might probably be because of the viscosity of the tolane products (they are crystalline compounds at room temperature). These results serves though as a basis for further improvements in molecular design.

The UV spectrum of compound 7 was recorded in chloroform as a dilute solution and it is shown in Figure 4. Two major absorption peaks are observed at 326 and $343 \mathrm{~nm}$.

TABLE III E-O Properties

\begin{tabular}{lcc}
\hline & LC1 & LC2 \\
\hline $\mathrm{V}_{10}(\mathrm{~V})$ & 0.937 & 1.018 \\
$\mathrm{~V}_{90}(\mathrm{~V})$ & 1.196 & 1.333 \\
$\mathrm{~V}_{90} / \mathrm{V}_{10}$ & 1.276 & 1.309 \\
$\tau_{\text {rise }}(\mathrm{ms})$ & 50.91 & 54.05 \\
$\tau_{\text {fall }}(\mathrm{ms})$ & 25.04 & 28.68 \\
\hline
\end{tabular}




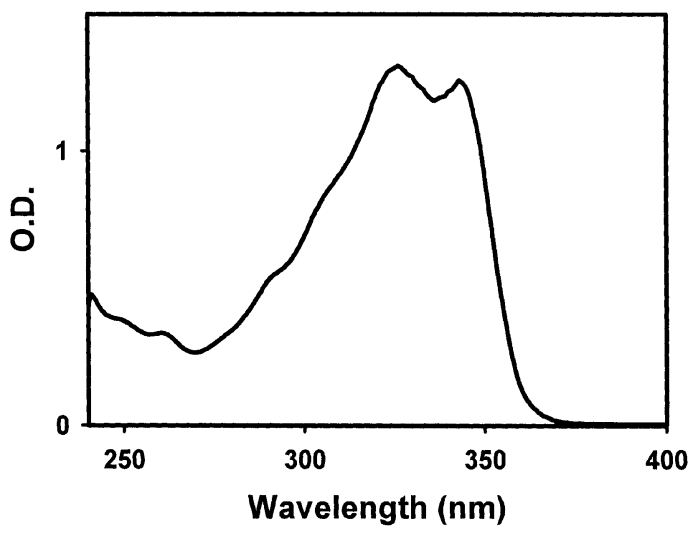

FIGURE 4 UV absorption spectrum of compound 7 in chloroform.

We expose the cell containing LC1 mixture at a UV dosage of $\sim 4.8 \mathrm{~J} / \mathrm{cm}^{2}$, the results being presented in Figure 5, a and $\mathrm{b}$. Analyzing this figure one may say that the NCS based tolane compound is stable at this UV dosage.

As one can see, the electro-optical properties of the irradiate sample cell looks almost the same with those of the non-irradiate cell. The T-V curve (Fig. 5a) of LC1 after UV irradiation shows lower transmittance at higher voltage, although the change in transmittance value is irrelevant within the high voltage region. The same trend is observed on the T-t curve $\left(\tau_{\text {on }}\right.$ curves) (Fig. 5b) at longer time. Further investigation should be made to fully understand this phenomenon.

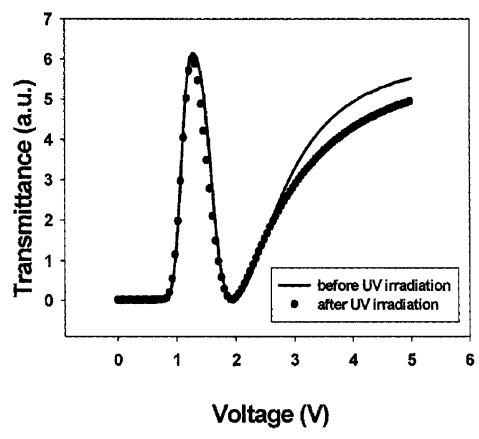

(a)

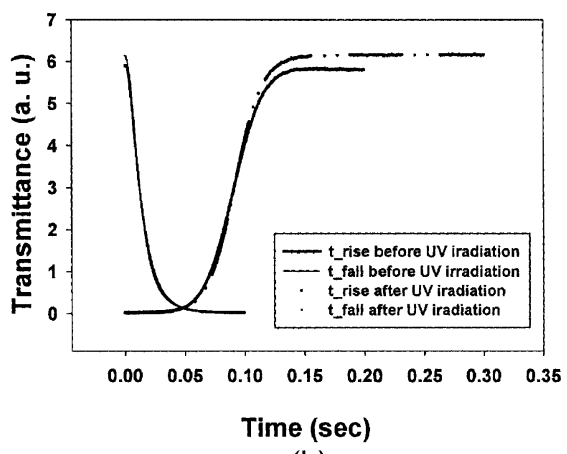

(b)

FIGURE 5 a) T-V curve for LC1 before and after UV irradiation; b) T-t curve for LC1 before and after UV irradiation. 


\section{CONCLUSIONS}

We synthesized a series of new NCS based tolane substances that have high birefringence and dielectric anisotropy, good solubility in LC host, relatively low melting points and fairly good UV stability. The mixture studies reveals that a wider nematic range can be obtained. In addition, we also observed a smectic phase by mixing polar compounds. LC devices can use thinner cell gap to achieve fast switching time with similar optical response because of the intrinsic physical properties (high birefringence and high dielectric anisotropy) of the dopant in a LC mixture.

\section{REFERENCES}

[1] Tarumi, K., Bremer, M., \& Geelhaar, T. (1997). Annu. Rev. Mater. Sci., $27,423$.

[2] Geelhaar, T. (1998). Liq. Cryst., 24 (1), 91.

[3] Scheffer, T. \& Nehring, J. (1995). Liquid Crystals, Applications and uses (B. Bahadur, World Scientific), 1, 231.

[4] Tarumi, K., Bartmann, E., Geelhaar, T., Schuler, B., Ichinose, H., \& Numata, H. (1995). Asia Display '95, 559.

[5] Nakajima, S., Sugiyama, Y., Ichinose, H., Numata, H., \& Naemura, S. (2000). SID'00 Digest, 242.

[6] Ichinose, H., Nakajima, S., Sugiyama, Y., Numata, H., \& Naemura, A.

[7] Manabe, Journal of the SID 9/4, 287 (2001). 